\title{
Rapid regeneration of stable transformants in cultures of potato by improving factors influencing Agrobacterium-mediated transformation
}

\author{
Bipasha Chakravarty, Gefu Wang-Pruski
}

Department of Plant and Animal Sciences, Nova Scotia Agricultural College, Truro, Canada.

Email: bipasha123@rediffmail.com; gwangpruski@nsac.ca

Received 4 August 2010; revised 25 August 2010; accepted 8 September 2010.

\begin{abstract}
An efficient and rapid Agrobacterium tumefaciensmediated transformation protocol was developed to generate activation-tagged mutant lines with the aim of large-scale functional analysis of the potato genome. The explants were inoculated with an Agrobacterium strain harboring the binary plasmid pSKI074 containing four CaMV 35S enhancers in the T-DNA region which activates the downstream genes in the host plant after its integration. Various parameters investigated to increase transformation efficiency were the type and age of explant, cultivar, hormone combinations, preculture of explants, period of co-cultivation with bacteria and concentration of bacterial cultures used for transformation. Stem explants from 5 week old plantlets of cv. Bintje which had undergone phytohormone pretreatment for 4 days, inoculation with diluted bacterial concentration of $\mathrm{OD}_{600}=0.2$ containing acetosyringone followed by 2 days of co-cultivation and selection in media with IAA and trans-zeatin all helped in greatly improving the transformation efficiency. The total time required from infection to rooted shoots was 6-7 weeks. Initial evidence for stable integration and expression of the transgenes by PCR analysis showed that over $93 \%$ of the regenerated lines were transgenic and this was confirmed by Southern hybridization.
\end{abstract}

Keywords: Bacterial Concentration; Cultivar; Explant; Potato Transformation; Preculture

\section{INTRODUCTION}

Although there are numerous regeneration and transformation protocols reported in potato, many of these have long regeneration periods and low frequecies [1-3]. In many reports an intermediate callus phase occurs [4] which increases regeneration time and also promotes dedifferentiation leading to somaclonal variants since potato is extremely sensitive to somaclonal variation in culture [5]. Moreover, transformation protocols in potato are genotype-dependent, limiting their usage and making practical applications not easily adaptable to all genotypes [6-8]. Previous reports indicated that the competence of plant cells for transformation via Agrobacterium-mediated gene transfer could be modified by adjusting physical conditions of the explant or media composition just prior to or during T-DNA delivery [9].

This paper describes the efforts on assessing and improving previous protocols and also selection of the best cultivar and explant to develop a rapid and efficient transformation and regeneration system in potato. The aim of the present investigation was thus to develop a protocol that could produce large numbers of potato transformants with stable integration of the transgenes within a short time. This system was used to generate a large number of activation-tagged mutant lines with the goal of large-scale functional analysis of the potato genome.

Using several cultivars and explants, the effectiveness of various factors that increase competence for transformation in recalcitrant explants or genotypes such as phytohormone pretreatment, hormone combinations in the regeneration medium, increasing period of co-cultivation, concentration of bacterial cultures, and age of explants was explored to select the best conditions for rapid transformation and regeneration in potato. The stable integration of transgenes in the transformed lines was analyzed by PCR and further confirmed by Southern hybridization.

\section{MATERIAL AND METHODS}

\subsection{Stock Plants and Explant}

Five different cultivars of potato, Solanum tuberosum L: 
Superior, Bintje, Atlantic, Shepody and Russet Burbank, were evaluated for their regeneration ability. Since transformation rate greatly depends on the cultivars, these five cultivars which are widely grown in Atlantic Canada were assessed for their ability to give the best results in our study. Sterile stock plantlets of potato were initially provided by New Brunswick Department of Agriculture and Fisheries, and the explants (4-6 mm) were cut from internodal stem and leaf sections. The stock plants were maintained in plantlet growth medium (PGM) containing MSMO salts (MS minimal organics, Sigma, Oakville, ON) with $3 \%$ sucrose, $\mathrm{pH}$ of 5.7 and solidified with $0.22 \%$ gelrite (Sigma, Oakville, ON). Cultures were incubated under a 16/8 h light/dark photoperiod at a temperature of $20 \pm 2{ }^{\circ} \mathrm{C}$.

\subsection{Agrobacterium Strain and Culture}

The Agrobacterium tumefaciens strain GV3101 harboring the plasmid vector pMPRK90 was obtained from the Salk Institute, Cologne. The plasmid pSKI074 from E.coli JM109 strain was introduced into the Agrobacterium cells by electroporation. The T-DNA construct contained four $35 \mathrm{~S}$ enhancers as well as the nptII gene for kanamycin resistance. It was grown on YEB medium con-

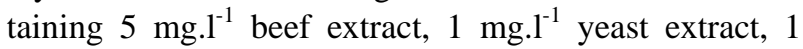
mg. $\mathrm{l}^{-1}$ peptone, $5 \mathrm{mg} . \mathrm{l}^{-1}$ sucrose and $10 \mathrm{mg} . \mathrm{l}^{-1} \mathrm{MgSO}_{4} .7$ $\mathrm{H}_{2} \mathrm{O}$, pH of 7.3. Antibiotics used for selection of the plasmid in bacteria were $100 \mathrm{mg}^{-1}{ }^{-1}$ ampicillin and 50 mg. $\mathrm{l}^{-1}$ gentamycin. Bacterial suspensions of transformed Agrobacterium colonies initiated from $-80^{\circ} \mathrm{C}$ glycerol stocks were derived from overnight cultivation of single colonies in liquid YEB media at $28^{\circ} \mathrm{C}$ on a rotary shaker at $200 \mathrm{rpm}$. Cultures were centrifuged at $3000 \mathrm{rpm}$ for $10 \mathrm{~min}$ to pellet the cells, resuspended and diluted in three volumes to adjust cell density to $\mathrm{OD}_{600}=0.2,0.4$, 0.6 for inoculation of the explants.

\subsection{Preculture and Co-Cultivation}

Explants were excised from 4-8 week old sterile plantlets and precultured on callus growth medium (CGM) containing MSMO salts, $2 \%$ glucose, $0.02 \%$ L-glutamine, $0.04 \%$ adenine sulphate, $0.05 \%$ of $2-\mathrm{N}$-morpholinoethane sulphonic acid (MES) and $0.05 \%$ of polyvinyl pyrrolidone (PVP) with a $\mathrm{pH}$ of 5.7 and solidified with $0.22 \%$ gelrite. The phytohormones: trans-zeatin, IAA, NAA, 2,4-D, BAP and zeatin riboside were filter sterilized and added after autoclaving the medium in five different combinations and concentrations as described in Table 4. Preculturing was carried out for 0-6 days in CGM containing the auxins and cytokinins for callusing and regeneration. After preculture, explants were immersed in infection medium (IM) containing MSMO salts, 3\% sucrose, $0.05 \%$ MES, $2 \%$ mannitol with $\mathrm{pH}$ of 5.5 . To this medium 0.148M acetosyringone was added and different volumes of bacterial suspension were adjusted for $\mathrm{OD}_{600}$ to $0.2-0.6$. The explants were immersed in IM for 2-5 min, blotted dry on sterile filter paper and placed on CGM for co-cultivation. Bacterial co-cultivation was performed at $20 \pm 2^{\circ} \mathrm{C}$ in the dark for 2-3 days.

\subsection{Selection and Regeneration of Transformants}

The explants incubated with bacteria were rinsed thoroughly with sterile distilled water containing 300 mg. $\mathrm{l}^{-1}$ claforan (Aventis Pharma Inc. Canada) to prevent further bacterial growth, blot-dried and transferred to callus selection medium (CSM) which was similar to CGM but with addition of the antibiotics kanamycin (100 mg. $\mathrm{l}^{-1}$ ) and claforan (300 mg. $\mathrm{l}^{-1}$ ) for selection of transformed regenerants. Regenerating explants were transferred from CSM after 3-4 weeks to shoot growth medium (SGM) containing the same composition as CSM but with absence of auxin for further growth and elongation of shoots. Shoots with 2-3 leaflets were cut out and placed for rooting on the medium without hormones

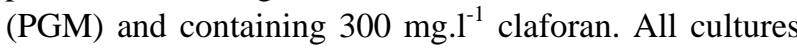
were maintained under $16 \mathrm{~h}$ photoperiod at a light intensity of $100 \mu \mathrm{E} \mathrm{m}^{-2} \mathrm{~s}^{-1}$ and a temperature of $20 \pm 2^{\circ} \mathrm{C}$. Each experiment was performed with 100 explants with 20 explants contained in each Petriplate. The total number of explants showing callusing, shoot-bud regeneration and total regenerated plantlets from each experiment using 100 explants was recorded.

\subsection{PCR Analysis and Southern Hybridization}

Transformed bacterial colonies used for the infection of explants were subjected to PCR analysis after 3 days growth in YEB medium just prior to infection. Colony PCR of bacterial colonies was carried out following a standard method [10]. The presence of the plasmid was detected by PCR amplification of a 450bp fragment using forward FRED primer (Sequence 5'- GCG TGG CTT TAT CTG TCT TTG TAT TG -3’) and reverse RED primer (Sequence 5'- GGC CTA CTT TAA TTG CTT CCA GTG TTA -3’) to confirm the presence of the plasmid pSKI074. PCR analysis was performed in a BioRad iCycler and the PCR product was visualized on an ethidium bromide stained agarose gel. Since the enhancers are very unstable, fresh plates were streaked from $-80^{\circ} \mathrm{C}$ stock for each experiment. The putative transformants were also subjected to PCR analysis by extracting the total genomic DNA of individual plants following the CTAB extraction method [11] and confirming the presence of the plasmid. To ascertain that amplification is caused by the plasmid and not endoge- 
nous Agrobacterium colonies, the transformed plantlets were also subjected to PCR using virG primer which amplifies only the virulence region of the bacteria. For Southern blot analysis, 1-2 $\mu \mathrm{g}$ of total genomic DNA isolated from the plantlets (see method above) was digested by the restriction enzyme EcoRI, for $16 \mathrm{~h}$ at $37^{\circ} \mathrm{C}$ before separation by electrophoresis on a $0.7 \%(\mathrm{w} / \mathrm{v})$ agarose gel at $50 \mathrm{~V}$ for $6 \mathrm{~h}$. The enzyme EcoRI has two cutting sites in the T-DNA at 8750 and $9740 \mathrm{bp}$ releasing a 990 bp fragment. About 25 pg of pSKI074 cut by EcoRI was used as positive control. The DNA was denatured and blotted onto a positively charged Hybond-XL nylon membrane (Amersham Biosciences, UK) and fixed to the membrane by baking at $80^{\circ} \mathrm{C}$ for $1 \mathrm{~h}$. The 990 bp fragment from pSKI074 harvested and purified was labeled with $\left[{ }^{32} \mathrm{P}\right]$-dCTP and used as probe. Hybridization was carried out at $45^{\circ} \mathrm{C}$ for $16-18 \mathrm{~h}$ and the blots washed twice with 2xSSC, $0.1 \%$ SDS for 5 min each time, followed by washing with $1 \mathrm{xSSC}, 0.1 \%$ SDS for $5 \mathrm{~min}$ and a final wash at $0.1 \mathrm{xSSC}, 0.1 \%$ SDS for 15 min all at $47^{\circ} \mathrm{C}$. The blots were exposed to X-ray film (Kodak XAR) for $14 \mathrm{~h}$ at $-80^{\circ} \mathrm{C}$.

\subsection{Statistical Analysis}

Each experiment was initiated with 100 explants and was replicated three times. The percentage of callusing and regeneration was scored on the basis of number of explants showing the response in each Petriplate containing 20 explants. The final number of plantlets regenerating from a total of 100 explants was noted at the end of each experiment. Statistical analysis was carried out for callus induction and shoot regeneration data for interactions between type of explants (leaf or stem) and cultivars using two-way ANOVA. All significant differences between means were found at $P<0.05$. The Statistical Analysis System (SAS for Windows, Ver. 8.2, 2001) was used for ANOVA (Proc GLM) and comparison of means.

\section{RESULTS AND DISCUSSION}

\subsection{Influence of Explants and Hormones}

Callusing and regeneration response was more rapid in the stem explants than leaf explants in all the cultivars studied and in the medium reported previously [4]. Moreover, leaf explants are delicate and more easily injured during manipulation especially in potato plantlets which result in low transformation rate and higher somaclonal variations [12]. Stem explants not only showed better in vitro response but are reportedly more convenient for conducting transformation experiments [13]. Of the different cultivars studied, Bintje showed the best regeneration response although Shepody showed best callusing (Table 1). The quality of callus formed in Shepody was white, soft and watery whereas Bintje formed green, nodular and friable callus (Figure 1(a)) that showed better regeneration ability. Callus formation was very prolific in Shepody and Superior, but these calli did not show good regeneration potential. The callus produced in Bintje, although showing less growth, gave better regeneration results and initiated more shoots on transfer to shooting medium within 4 weeks (Table 1).

Thus, due to the high quality of callus and regeneration ability, the cv. Bintje and stem explants were selected for all further experiments. These results confirmed the genotypic variations in responses observed previously in potato [14] and also shows that the type of callus formed influences the regeneration potential of the plant [15]. Statistical analysis as shown by two-way ANOVA, revealed highly significant effects of cultivars and explants and their interactions on both callusing and regeneration responses (Tables 2 and 3).

Different concentrations and combinations of auxins and cytokinins were investigated according to previously reported protocols. The hormones NAA at $0.1 \mathrm{mg} . \mathrm{l}^{-1}$ and

Table 1. Percentage of callus and regeneration response in different explants and cultivars after 4 weeks of culture.

\begin{tabular}{ccccc}
\hline \multirow{2}{*}{ Cultivar } & \multicolumn{2}{c}{ \% Callusing * } & \multicolumn{2}{c}{ \% Regeneration ** } \\
\cline { 2 - 5 } & Stem & Leaf & Stem & Leaf \\
\hline Superior & $60.2 \pm 6.15 \mathrm{bA}$ & $0 \mathrm{~dB}$ & $23.8 \pm 4.38 \mathrm{bA}$ & $0 \mathrm{cB}$ \\
Bintje & $27.4 \pm 3.36 \mathrm{cA}$ & $21.2 \pm 2.58 \mathrm{bA}$ & $45.1 \pm 4.30 \mathrm{aA}$ & $14.8 \pm 2.38 \mathrm{aB}$ \\
Atlantic & $31.2 \pm 2.86 \mathrm{cA}$ & $12.8 \pm 1.92 \mathrm{cB}$ & $0 \mathrm{cA}$ & $10 \pm 3.8 \mathrm{bB}$ \\
Shepody & $86.7 \pm 9.51 \mathrm{aA}$ & $32.8 \pm 4.96 \mathrm{aB}$ & $20 \pm 7.17 \mathrm{bA}$ & $0 \mathrm{cB}$ \\
Russet Burbank & $33.4 \pm 7.3 \mathrm{cA}$ & $12.4 \pm 3.64 \mathrm{cB}$ & $25.2 \pm 3.03 \mathrm{bA}$ & $8.6 \pm 4.82 \mathrm{bB}$ \\
\hline
\end{tabular}

*Number of explants with callus/total number of explants per Petriplate. **Number of explants with shoot-buds/total number of explants per Petriplate. Small letters denote significance between cultivars whereas capital letters denote significance between explants. Values followed by the same letter are not significantly different from each other. 


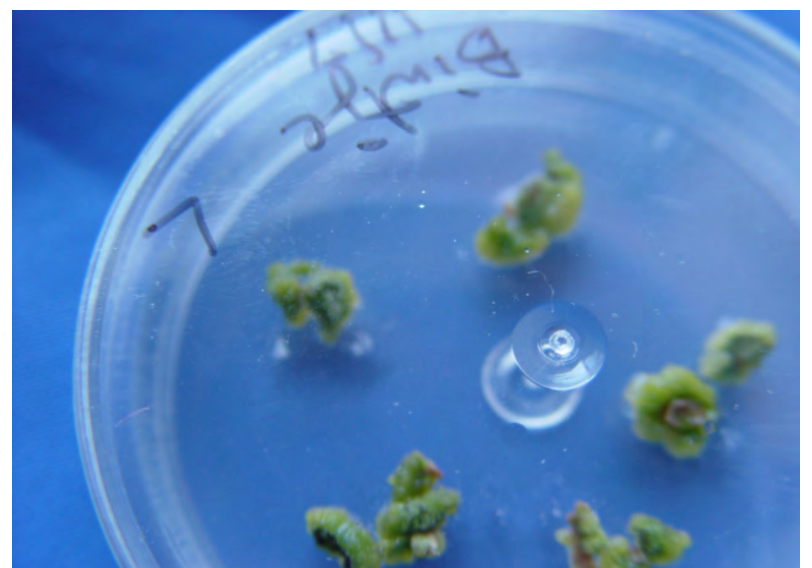

(a)

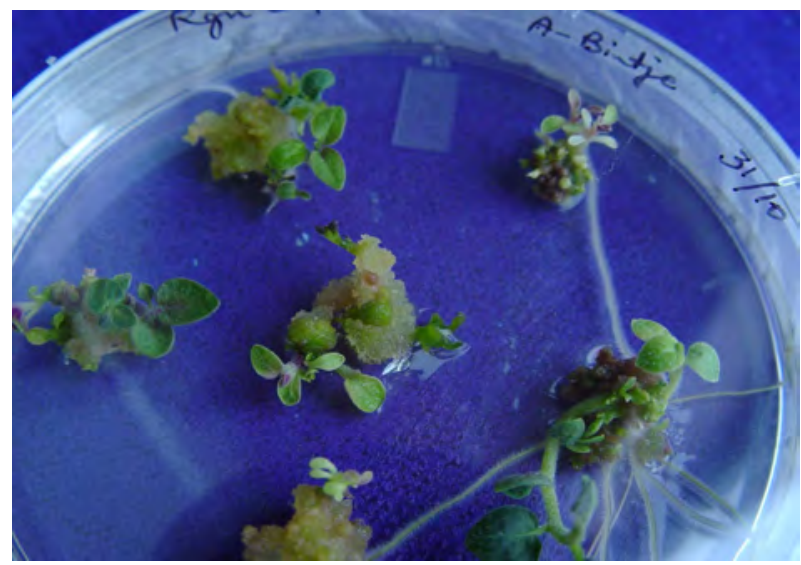

(c)

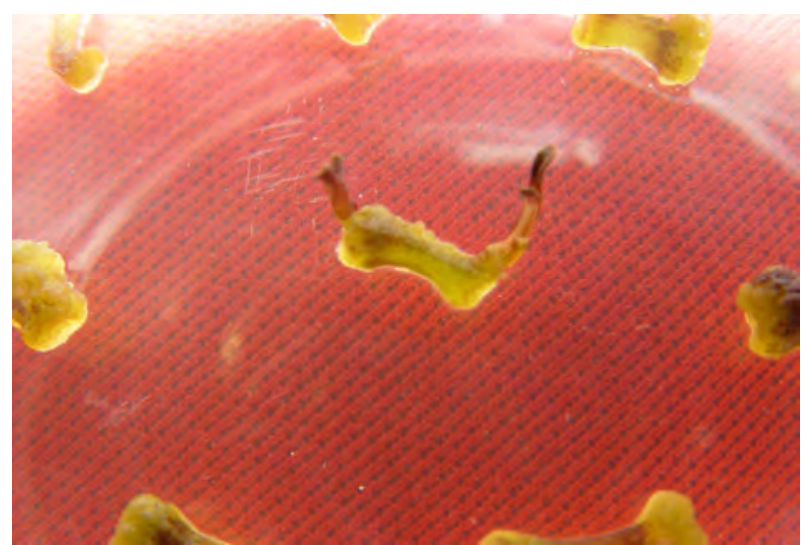

(e)

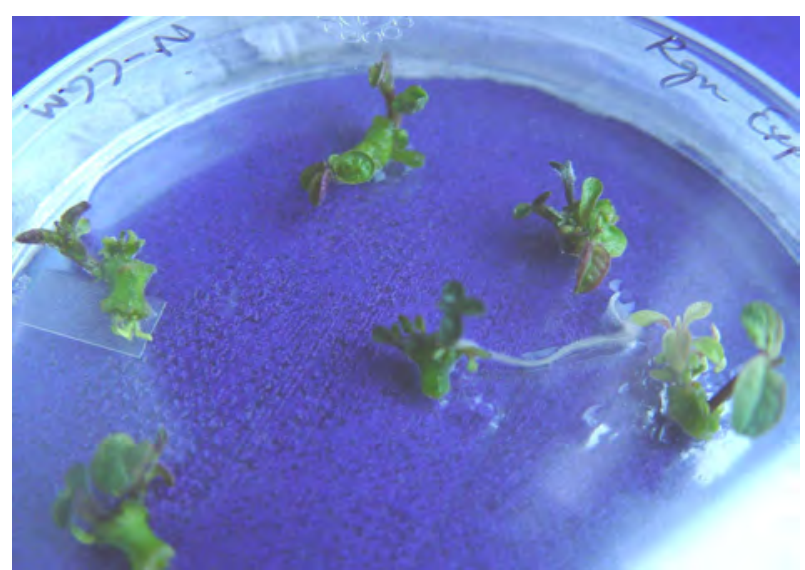

(b)

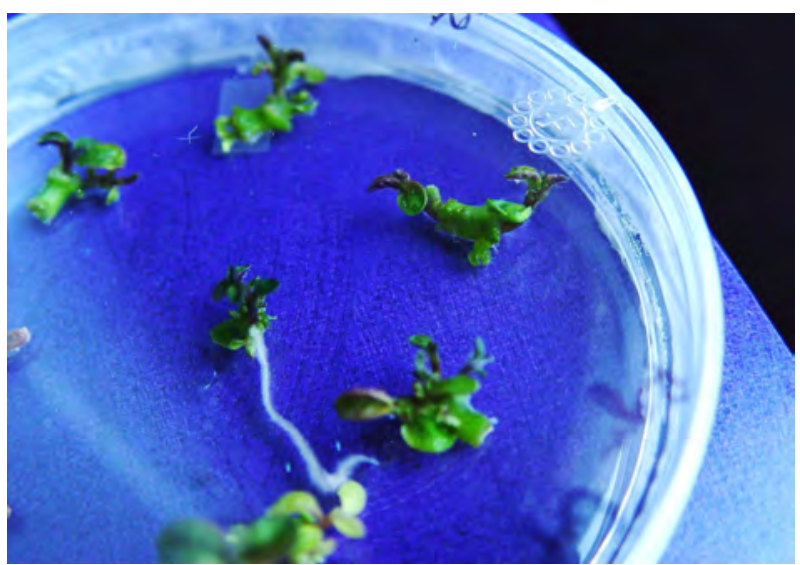

(d)

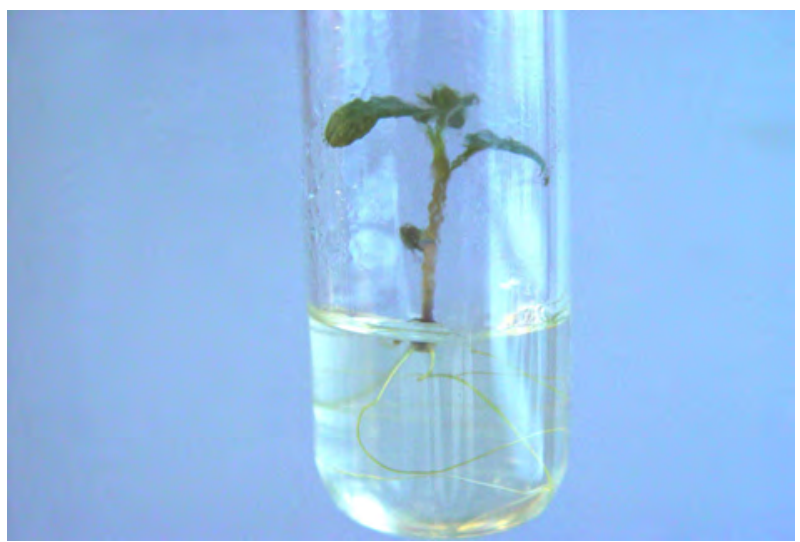

(f)

Figure 1. Stages of regeneration after transformation events. (a) Callus initiated from cultivar Bintje stem explant. (b) Shoots regenerating from stem explants with minimal callus in CGM media with IAA and t-zeatin without antibiotics. (c) Explants showing shoots with callus in medium with NAA and t-zeatin. (d) Shoots growing on SGM medium with t-zeatin. (e) Shoots regenerating from the two ends of stem explants in CSM media with IAA and t-zeatin containing kanamycin. (f) A complete transformed plantlet showing rooting in medium without hormones.

trans-zeatin at $1 \mathrm{mg}^{-1} \mathrm{l}^{-1}$ showed better response than the same hormones used in reverse concentrations. But an intermediate callus phase was formed that took more time to regenerate into shoots (Figure $\mathbf{1 ( c ) )}$ on transfer to the shooting medium without NAA. Addition of the hormones BAP and 2,4-D to the medium showed good 
Table 2. Two-way analysis of variance of the cultivars and explants on the percentage of callusing based on data presented in Table 1.

\begin{tabular}{cccccc}
\hline Variable & $\boldsymbol{d} \boldsymbol{f}$ & SS & MS & F & P \\
\hline Cultivar & 4 & 9961.3 & 2490.3 & 99.65 & $<0.0001$ \\
Explant & 1 & 12640.5 & 12640.5 & 505.82 & $<0.0001$ \\
$\begin{array}{c}\text { Cultivar x } \\
\text { explant }\end{array}$ & 4 & 5540.2 & 1385.1 & 55.42 & $<0.0001$ \\
Error & 40 & 999.6 & 25.0 & & \\
\hline
\end{tabular}

Table 3. Two-way analysis of variance of the cultivars and explants on the percentage of regeneration based on data presented in Table 1.

\begin{tabular}{cccccc}
\hline Variable & $\boldsymbol{d} \boldsymbol{f}$ & SS & MS & $\mathrm{F}$ & $\mathrm{P}$ \\
\hline Cultivar & 4 & 3635.88 & 908.97 & 63.79 & $<0.0001$ \\
Explant & 1 & 3152.18 & 3152.18 & 221.21 & $<0.0001$ \\
$\begin{array}{c}\text { Cultivar x } \\
\text { explant }\end{array}$ & 4 & 2343.72 & 585.93 & 41.12 & $<0.0001$ \\
Error & 40 & 570.00 & 14.25 & & \\
\hline
\end{tabular}

callusing in the transformed tissues, but on transfer to shooting medium devoid of 2,4-D, the regeneration frequency was low (Table 4). Using the hormone combinations of 2,4-D and zeatin riboside showed a higher regeneration rate compared to other protocols but an intermediate callus phase increased the time required for regeneration and also increases the likelihood of obtaining somaclonal variants. Direct shoot regeneration from the explants without introducing a callus phase gives a much higher regeneration efficiency [16,17]. The addition of $t$-zeatin or zeatin riboside to the medium was found to be more effective for regeneration of shoots and also produced less calli (Figure 1(b)) as compared to those without zeatin [18]. Another hormone combination with GA and BAP [19] did not show promising results. The combination of IAA and $t$-zeatin in different concentrations were tested and the best result was obtained at $0.1 \mathrm{mg} . \mathrm{l}^{-1}$ of each (Table 4) showing direct shoot regeneration from explants with minimal callus (Figure 1(e)). This hormone combination was finally selected and applied in CGM and CSM and followed for all further experiments. Further growth and elongation of shoots could be promoted after 3 weeks on transfer of explants to SGM with absence of IAA.

\subsection{Pretreatment Studies}

To investigate the effects of preculture in phytohormones, the stem explants were precultured on CGM containing $0.1 \mathrm{mg}^{-1} \mathrm{l}^{-1}$ each of IAA and t-zeatin for 0-6 days. The explants with preculture of 2, 4 or 6 days showed $10-30 \%$ increase in regeneration response in comparison to non-precultured (0 day) explants (Figure 2(a)) that has also been observed in other plants [20,21]. The highest shoot regeneration ability was observed after 4 days of preculture and a further period of preculture did not show any enhancement unlike previous report that indicates decline in differentiation rates after 2 days of preculture [22]. The precultured explants not only gave better shoot regeneration, but also showed less bleaching in kanamycin-containing medium and less susceptibility to overgrowth of Agrobacterium cultures. The preculture of explants in phytohormones before co-cultivation is important for transformation and may have an effect at various steps including during T-DNA integration. Phytohormone pretreatment activates cell division and the phase of cell-cycle influences stable transformation, since formation of new and thin cell walls probably influences specific attachment capacity to Agrobacterium [23]. The presence of an induction agent, such as acetosyringone in the inoculation media was also crucial for efficient T-DNA delivery and improving transformation rate as reported earlier [24]. Acetosyringone reportedly activates the transcription of Agrobacterium virulence genes that can greatly increase the transformaton rate.

The cell-density for inoculation and period of co-cultivation with bacterial culture also influences the transformation efficiency. Although prolonging the inoculation and co-cultivation time period usually yields more efficient T-DNA delivery, but higher cell-damage and necrosis occurs and leads to death of tissues. Thus, 2 days of co-cultivation showed better results as compared to 3 days (Figure 2(b)) and diluting the bacterial suspension to $\mathrm{OD}_{600}=0.2$ (Figure 2(c)) significantly increased the transformation rate which confirms previous findings [24-26]. Diluting the bacterial concentration also reduced the number of explants with overgrowth of bacteria thus increasing the viability period of the explants in regeneration media. Another factor influencing T-DNA delivery was the age of the explants. Explants taken from 5 week old plantlets (Figure 2(d)) showed optimum results whereas explants from older plantlets had more hard tissues that decreased regeneration response and greatly brought down the transformation efficiency. The results showed that physiological state of the starting material is also important to ensure successful transformation.

Shoots regenerated from the stem explants in selection medium containing kanamycin (CSM) with minimal calli within 4 weeks (Figure 1(e)) and subculture of the regenerating explants to shooting media without auxin (SGM) could promote further elongation and growth of shoots. Although numerous shoots were produced from 
Table 4. Regeneration response of stem explants in medium with different hormone combinations and concentrations.

\begin{tabular}{|c|c|c|c|c|c|}
\hline \multicolumn{2}{|c|}{ Hormones combinations and concentrations } & \multirow{2}{*}{ Callus (\%)* } & \multirow{2}{*}{ Shoots $(\%)^{* *}$} & \multirow{2}{*}{ \#Plants*** } & \multirow{2}{*}{$\begin{array}{l}\text { Rgn time in } \\
\text { weeks }\end{array}$} \\
\hline CGM (mg. $\left.\mathbf{l}^{-1}\right)$ & SGM (mg. $\left.\mathbf{l}^{-1}\right)$ & & & & \\
\hline NAA (0.1)+t-zeatin (1) & $t$-zeatin (1) & $82 \pm 3.6$ & $22.8 \pm 4.1$ & 19 & 10 \\
\hline BAP (0.5) + 2,4-D (2) & BAP (0.5) & $67 \pm 3.2$ & $20 \pm 2.7$ & 15 & 18 \\
\hline 2,4-D (2) + ZR (0.8) & ZR (0.8) & $88 \pm 4.9$ & $42 \pm 5.5$ & 32 & 10 \\
\hline No hormones & $\mathrm{BAP}(2.5)+\mathrm{GA}(1)$ & $76 \pm 5.4$ & $15 \pm 3.6$ & 8 & 14 \\
\hline IAA $(0.1)+t$-zeatin $(0.1)$ & $t$-zeatin $(0.1)$ & $50.4 \pm 4.3$ & $38.2 \pm 3.8$ & 25 & 7 \\
\hline
\end{tabular}

*Number of explants with callus/total number of explants. **Number of explants with shoot-buds/total number of explants. ***Total number of plants regenerating in each experiment. CGM indicates medium for callus and SGM medium for shoot initiation.

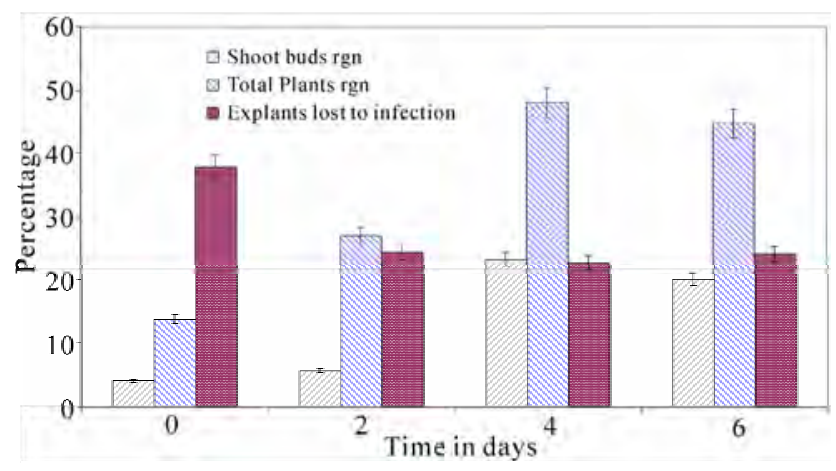

(a)

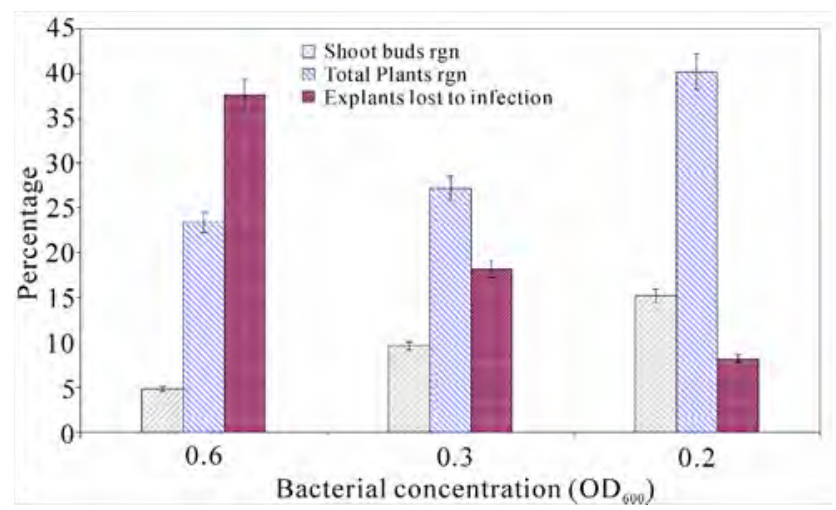

(c)

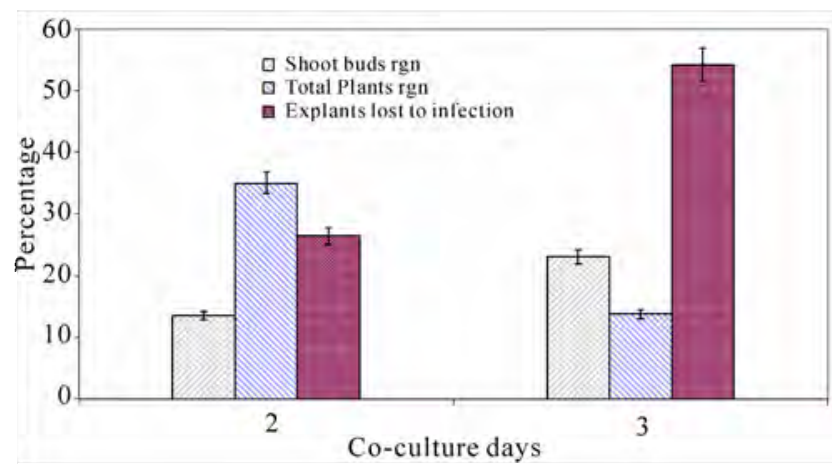

(b)

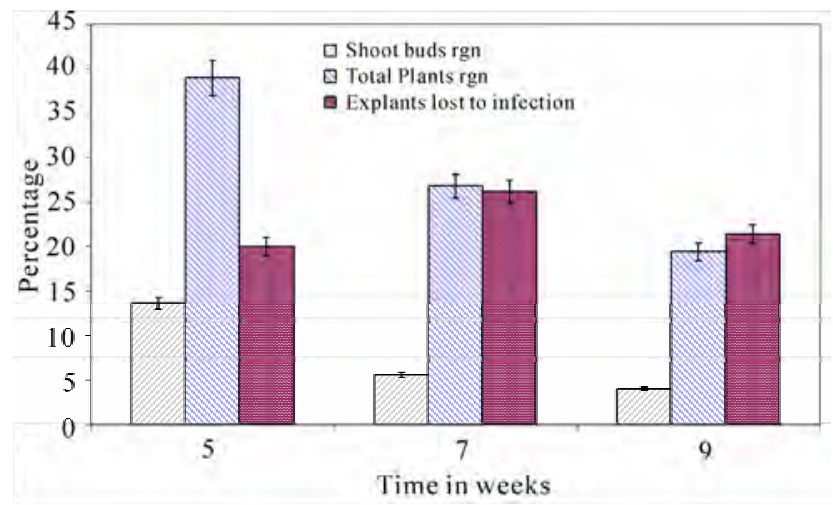

(d)

Figure 2. Bar charts showing variation in the percentages of regeneration of shootbuds and total plants regenerated from stem explants due to the effect of different factors. (a) Effect of preculture. (b) Effect of co-culture. (c) Effect of bacterial concentration and (d) Effect of age of explants.

each explant, only one shoot was taken from each end to generate independent transgenic events. This signicantly avoided the collection of duplicated clones. Frequent subcultures to fresh media every 2-3 weeks were necessary to prevent growth of claforan-resistant bacteria on the explants. Frequent transfers to fresh selection medium also enhanced the transformation rate probably because untransformed tissues die and release toxic compounds. About $85-90 \%$ of shoots showed rooting after transferring to media devoid of hormones and developed into complete plantlets within 7 weeks of culture (Figure 1(f)). Cultures over 8 weeks old started showing bleaching in the explants due to presence of kanamycin in the medium and had to be discarded. Some of them showed abnormal albino shoots and did not root, which were probably non-transgenic escapes. Vigorous 
rooting and further growth in selection media were good indicators of successful transformation.

\subsection{PCR and Southern Hybridization Results}

PCR analysis confirmed the presence of 450 bp product indicating the presence of the plasmid in the regenerants (Figure 3(a)). A total of 80 regenerated plants were subjected to PCR analysis and of these, 75 were PCR-positive indicating that over $93 \%$ of the regenerated plants were transgenic with successful integration of the actvation-tagged plasmid into the genome of the plants. Of these plants, 60 were regenerated from precultured explants, and 58 were PCR positive, whereas of 20 plants regenerated from non-precultured explants, 17 were positive. The use of virG primer which amplifies only the virulence region of the plasmid showed negative results for all the transformed plants (Figure 3(b)) indicating that the amplification is not due to the presence of endogenous bacterial colonies in the transformants. Results of Southern hybridization experiments have shown the presence of the 990bp fragment in the transformed plantlets (Figure $3(\mathbf{c})$ ) thus confirming the presence of the plasmid and reinstating successful and stable integration of the transgene.

\section{CONCLUSIONS}

In conclusion, rapid transformation and regeneration in potato with minimal callus phase can be achieved by manipulating media and culture conditions before and during T-DNA delivery. This protocol not only reduces the regeneration time and callus phase but also gives greater number of shoots and stable transformed potato plants. Due to its high cooking and processing quality, Bintje is commercially a preferred cultivar in many European countries, but previous efforts have reported difficulty in regenerating large number of transgenic plants in this cultivar. The development of an efficient transformation protocol for this potato cultivar to generate a large number of independent transgenic lines as described here is crucial to carry out further work on functional genomics. The stable integration of transgenes in the transformed potato plants by this method as confirmed by PCR and Southern hybridization is due to the absence of dedifferentiation steps that are common

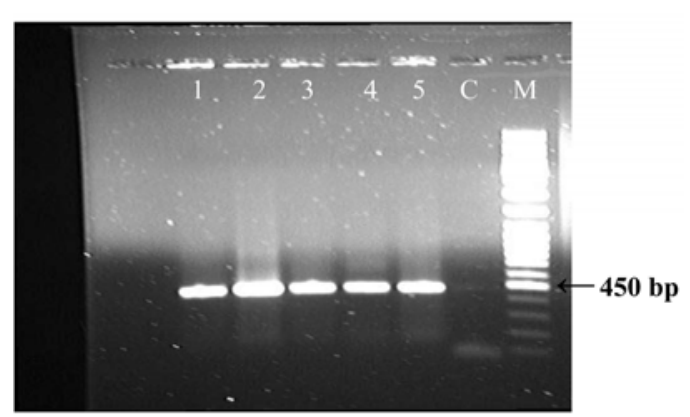

(a)

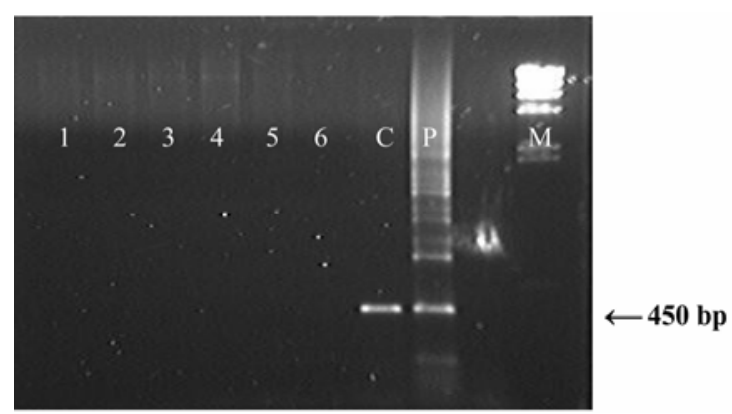

(b)

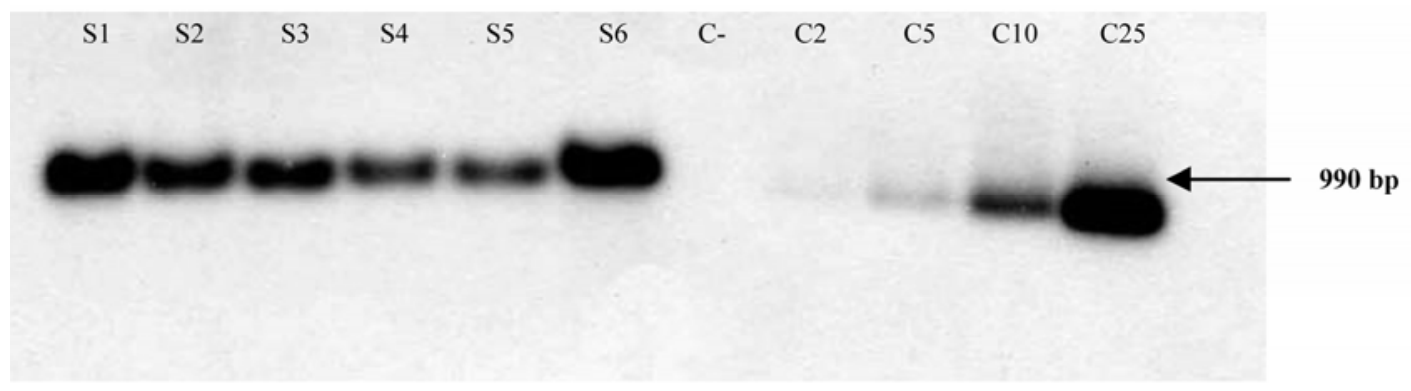

(c)

Figure 3. Verification of gene insertion by PCR (a) PCR analysis of transformants using 074 FRED and RED primers. Lane 1- 5: transformed plants \#1,2,3,4 and 5, C: control non-transformed plant, M: 100 bp ladder DNA molecular weight marker. (b) PCR analysis of transformed plants using virG primer. Lane 1-6: transformed plants \#1, 2,3,4,5 and 6. C: control non-transformed plant. P: plasmid pSKI074. M: High molecular weight 1 kbp DNA marker. (c) Southern hybridization analysis of EcoRI cut genomic DNA of plantlets transformed with pSKI074. Samples S1-S6 indicate transformed plants \#1,2,3,4,5 and 6. C- indicates the negative control untransformed plant and C2-C25 indicates the positive control EcoRI cut plasmid pSKI074 releasing a 990bp fragment with 2, 5, 10 and 25pg of DNA respectively. 
during initiation of callus.

\section{ACKNOWLEDGEMENTS}

Financial support for the Canadian Potato Genome Project from Genome Atlantic is gratefully acknowledged. We thank Shirlyn Coleman from New Brunswick Department of Agriculture, Fisheries and Aquaculture, for providing the potato stock plants.

\section{REFERENCES}

[1] An, G., Watson, B.D. and Chiang, C.C. (1986) Transformation of tobacco, tomato, potato and Arabidopsis thaliana using a binary Ti vector system. Plant Physiology, 81, 301-305.

[2] Romano, A., Raemakers, K., Visser, R. and Mooibroek, H. (2001) Transformation of potato (Solanum tuberosum) using particle bombardment. Plant Cell Reports, 20, 198-204.

[3] Chang, M.M., Culley, D., Choi, J.J. and Hadwiger, L.A. (2002) Agrobacterium-mediated co-transformation of a pea $\beta$-1,3-glucanase and chitinase genes in potato (Solanum tuberosum L. cv. Russet Burbank) using a single selectable marker. Plant Science 163, 83-89.

[4] De Block, M. (1988) Genotype-independent leaf disc transformation of potato (Solanum tuberosum) using Agrobacterium tumefaciens. Theoritical and Applied Genetics, 76, 767-774.

[5] Badr, A., Mabrouk, Y., Rakha, F. and Ghazy, A.H. (2008) Agrobacterium tumefasciens - mediated transformation of potato and analysis of genomic instability by RAPD. Research Journal in Agriculture Biological Science, 4(1), 16-25.

[6] Wenzler, H., Mignery, G., May, G., Park, W. (1989) A rapid and efficient transformation method for the production of large numbers of transgenic potato plants. Plant Science, 63, 79-85.

[7] Yee, S., Stevens, B., Coleman, S., Seabrook, J.E.A. and Li, X.-Q. (2001) High efficiency regeneration in vitro from potato petioles from intact leaflets. American Journal of Potato Research, 78, 151-157.

[8] Banerjee, A.K., Prat, S. and Hannapel, D.J. (2006) Efficient production of transgenic potato (S. tuberosum L. ssp. andigena) plants via Agrobacterium tumefaciensmediated transformation. Plant Science, 170, 732-738.

[9] Lin, Y.J. and Zhang, Q. (2005) Optimising the tissue culture conditions for high efficiency transformation of indica rice. Plant Cell Reports, 23, 540-547.

[10] Sambrook, J. and Russell, D.W. (2001) Molecular cloning: a laboratory manual. Vol. 2, 3rd edn. Cold Spring Harbor Laboratory Press, New York.

[11] Doyle, J.J. and Doyle, J.L. (1990) Isolation of plant DNA from fresh tissue. Focus, 12, 13-15.

[12] Soto, N., Enriquez, GA., Ferreira, A., Corrada, M., Fuentes, A., Tiel, K. and Pujol, M. (2007) Efficient transformation of potato stem segments from cv. Desiree using phosphinothricin as selection marker. Biotech Applicada, 24, 139-144.

[13] Beaujean, A., Sangwan, R.S., Lecardonnel, A. and
Sangwan-Norreel, B.S. (1998) Agrobacterium-mediated transformation of three economically important potato cultivars using sliced internodal explants: an efficient protocol of transformation. Journal of Experimental Botany, 49, 1589-1595.

[14] Heeres, P., Schippers-Rozenboom, M., Jacobsen, E., Visser, R.G.F. (2002) Transformation of a large number of potato varieties: genotype-dependent variation in efficiency and somaclonal variability. Euphytica, 124, 13-22.

[15] Christiansen, P., Andersen, C.H., Didion, T., Folling, M., Nielsen, K.K. (2005) A rapid and efficient transformation protocol for the grass Brachypodium distachyon. Plant Cell Reports, 23,751-758.

[16] Trujillo, C., Rodriguez-Arango, E., Jaramillo, S., Hoyos, R., Orduz, S. and Arango, R. (2001) One-step transformation of two Andean potato cultivars (Solanum tuberosum L subsp. andigena). Plant Cell Reports, 20, 637-641.

[17] Visser, R.G.F., Jacobsen, E., Hesseling-Meinders, A., Schans, M.J., Witholt, B. and Feenstra, W.J. (1989) Transformation of homozygous diploid potato with an Agrobacterium tumefaciens binary vector system by adventitious shoot regeneration on leaf and stem segments. Plant Molecular Biology, 12, 329-337.

[18] Turhan, H. (2004) Callus induction and growth in transgenic potato genotypes. African Journal of Biotechnology, 3, 375-378.

[19] Ooms, G., Burrell, M.M., Karp, A., Bevan, M. and Hille, J. (1987) Genetic transformation of two potato cultivars with T-DNA from disarmed Agrobacterium. Theoritical and Applied Genetics, 73, 744-750.

[20] Egnin, M., Mora, A. and Prakash, C.S. (1998) Factors enhancing Agrobacterium tumefaciens mediated gene tranfer in peanut (Arachis hypogaea L). In Vitro Cell Development Biology, 34, 310-318.

[21] Chateau, S., Sangwan, R.S. and Sangwan-Norreel, B.S. (2000) Competence of Arabidopsis thaliana genotypes and mutants for Agrobacterium tumefaciens-mediated gene transfer: role of phytohormones. Journal of $E x$ perimental Botany, 51, 1961-1968.

[22] Gould, J.H. and Magallanes-Cedeno, M. (1998) Adaptation of cotton shoot apex culture to Agrobacterium-mediated transformation. Plant Molecular Biology Report, 16, 1-10.

[23] Chen, S.C., Liu, H.W., Lee, K.T. and Yamakawa, T. (2007) High efficiency Agrobacterium rhizogenes-mediated transformation of heat inducible sHSP18.2-GUS in Nicotiana tabacum. Plant Cell Reports, 26, 29-37.

[24] Li, D., Zhao, K., Xie, B., Zhang, B. and Luo, K. (2003) Establishment of a highly efficient transformation system for pepper (Capsicum annuum L.). Plant Cell Reports, 21, 785-788.

[25] Wang-Pruski, G. and Szalay, A.A. (2002) Transfer and expression of the genes of Bacillus branched chain alpha-oxo acid decarboxylase in Lycopersicon esculentum. Electronic Journal of Biotechnology, 5, 141-153.

[26] Zaragoza, C., Munoz-Bertomeu, J. and Arrillaga, I. (2004) Regeneration of herbicide-tolerant black locust transgenic plants by SAAT. Plant Cell Reports, 22, 832-838. 